\title{
CONHECIMENTO E OPINIÃO DE MORADORES DE CAXIAS DO SUL SOBRE MORTE ENCEFÁLICA E DOAÇÃO DE ÓRGÃOS E TECIDOS PARA TRANSPLANTE
}

\section{Knowledge and opinion of residents of Caxias do Sul on encephalic death and organ and tissue donation for transplant}

\author{
Rafaela Souza da Silva, Janaína Samantha Martins de Souza
}

\section{RESUMO}

Objetivo: Identificar o conhecimento e opinião de uma amostra da população da cidade de Caxias do Sul sobre morte encefálica e doação de órgãos e tecidos para transplantes. Métodos: Estudo exploratório com abordagem quantitativa, realizado com 122 moradores do município de Caxias do Sul - Rio Grande do Sul, selecionados aleatoriamente, dentre a população acima de 18 anos. A coleta de dados foi realizada na sala de espera de uma instituição de assistência hospitalar de médio porte e em uma instituição de ensino superior privada, no período de agosto a setembro de 2018. Os dados foram analisados através do Software IBM SPSS, por meio de regressão linear e correlação de Pearson, considerando nível de significância de $p<0,05$. Resultados: A maioria dos participantes $(96,7 \%)$ é a favor da doação de órgãos e $(82,8 \%)$ autorizariam a doação de seus órgãos após a morte, sendo o principal motivador ajudar o próximo e salvar vidas. Os principais motivos contrários à doação são: apego ao familiar e religião. Muitos acreditam na existência de venda de órgãos no Brasil e que existe possibilidade de erro no diagnóstico de morte encefálica estabelecido pelo médico. A maioria já recebeu informações sobre doação de órgãos, principalmente através das mídias e dos profissionais de saúde. Conclusão: A maioria dos participantes tem atitude positiva em relação à doação de órgãos e apresentam conhecimento parcial sobre o processo de doação. Nota-se a necessidade de mais campanhas educativas e de incentivo à doação, pois quanto maior a compreensão da família, maior será a segurança no momento da decisão pela doação de órgãos.

Descritores: Obtenção de tecidos e órgãos; Transplante de Órgãos; Morte Encefálica; Conhecimento.

\section{Instituição:}

Curso Bacharelado em Enfermagem. Faculdade Nossa Senhora de Fátima, Caxias do Sul/RS, Brasil.

\section{Correspondência:}

Rafaela Souza da Silva

Rua Adalberto Wortmann, 240, CEP 95680-000, Canela/RS, Brasil. $\mathrm{T}(54)$ 99602-6033

rafaela.s1@hotmail.com
Aceito em: 10/01/2020

\section{INTRODUÇÃO}

O transplante de órgãos é, muitas vezes, o único tratamento que possibilita sobrevida a pacientes portadores de insuficiências terminais de diferentes órgãos. ${ }^{1}$ O processo de doação de órgãos e tecidos é o ato voluntário de doar uma ou mais partes do corpo para fins de transplante. A doação de alguns órgãos pode ser feita em vida ou após a morte com a confirmação do diagnóstico de morte encefálica. ${ }^{2}$

No Brasil, a regulamentação sobre a retirada de órgãos está prevista no Decreto 9.175/17, que dispõe sobre a remoção de órgãos, tecidos e partes do corpo 
Conhecimento e opinião de moradores de Caxias do Sul sobre morte encefálica e doação de órgãos e tecidos para transplante

humano para fins de transplante e tratamento e define que a remoção de órgãos para doação dependerá exclusivamente da autorização familiar. ${ }^{3}$

De acordo com o Ministério da Saúde, ${ }^{2}$ o Brasil conta com o maior programa público de transplantes do mundo, no qual cerca de $90 \%$ dos procedimentos são financiados pelo Sistema Único de Saúde (SUS). Desde o primeiro transplante realizado no Brasil em 1964, essa atividade teve evolução considerável em termos de variedade de órgãos transplantados e número de procedimentos realizados. ${ }^{2}$ Ainda assim, percebe-se um desequilíbrio entre oferta e demanda. Segundo o Registro Brasileiro de Transplantes (RBT), mais de 37 mil pacientes aguardam na lista de espera. ${ }^{4}$

Os principais obstáculos na efetivação da doação de órgãos são: falha na identificação e notificação de potenciais doadores, recusa familiar, parada cardíaca e contraindicações médicas. Mesmo o Brasil sendo o segundo país do mundo em número de transplantes, a recusa familiar ainda representa a maior causa da não concretização das doações. ${ }^{5}$

Em estudo realizado por Pessoa, Schirmer e Roza ${ }^{6}$ para investigar os principais motivos da negativa da família, constatou-se que uma das principais causas é a falta de conhecimento da população sobre o processo de doação de órgãos, entre outras, que incluem a falta de compreensão e dúvidas em relação ao diagnóstico de morte encefálica, causas religiosas, despreparo da equipe de saúde responsável em realizar a entrevista com a família e desconhecimento do desejo do familiar. Segundo a Associação Brasileira de Transplantes de Órgãos (ABTO), diante do diagnóstico de morte encefálica é necessária a confiança da população no sistema de doação e alocação de órgãos, bem como o comprometimento dos profissionais de saúde envolvidos, pois esse é um processo trabalhoso e delicado. ${ }^{7}$

Entende-se assim, que o número de doações poderia ser maior se a população fosse mais esclarecida sobre o assunto e tivesse mais acesso às informações que permeiam o processo de doação de órgãos. Desta forma, o presente estudo tem como objetivo identificar o conhecimento e a opinião de uma amostra da população da cidade de Caxias do Sul sobre morte encefálica e doação de órgãos e tecidos para transplantes.

\section{MÉTODOS}

Tratou-se de estudo exploratório com abordagem quantitativa, realizado no período de agosto a setembro de 2018 na sala de espera de instituição de assistência hospitalar de médio porte e em instituição de ensino superior privada, ambas localizadas na cidade de Caxias do Sul - Rio Grande do Sul. A amostra foi por conveniência, composta por 122 pessoas, com idade entre 18 e 72 anos.

Foi utilizado como instrumento para coleta de dados um questionário autoaplicável composto por 21 perguntas fechadas, o qual apresentava questões relativas ao conhecimento e à opinião dos entrevistados no que se refere ao processo de doação de órgãos e tecidos para transplante. O roteiro da coleta de dados foi desenvolvido pela pesquisadora, com base em um protocolo de pesquisa desenvolvido por Teixeira, Gonçalves e Silva. ${ }^{8}$ Os dados obtidos foram transcritos, analisados e agrupados em tabelas, utilizando o Software IBM SPSS Statistics. As análises foram feitas através de regressão linear e correlação de Pearson, tendo como nível de significância $p<0,05$.

Os critérios de inclusão do estudo foram: possuir idade igual ou superior a 18 anos, ser morador de Caxias do Sul há mais de seis meses, aceitar participar voluntariamente do estudo e assinar o Termo de Consentimento Livre e Esclarecido. A pesquisa foi aprovada pelo Comitê de Ética em Pesquisa da Associação Cultural e Científica Virvi Ramos (CAAE 96464818.9.0000.5523; parecer $n^{\circ}$ 2.854.385) e obedeceu a Resolução 466/2012 do Conselho Nacional de Saúde. ${ }^{9}$

\section{RESULTADOS}

Participaram da pesquisa 122 pessoas, prevalecendo mulheres, com $82 \%$. A maioria possuía nível superior incompleto $(61,5 \%)$ e apresentava como religião a católica $(58,2 \%)$. O perfil dos participantes está apresentado na Tabela 1.

Quanto ao posicionamento sobre a doação de órgãos, $96,7 \%$ dos participantes eram a favor da doação, $2,5 \%$ não tinham opinião formada e $0,8 \%$ eram contra. Também foi verificado se essa apreciação tem relação com a escolaridade, idade e religião. Identificou-se que a escolaridade $(p=0,018)$ influenciava a opinião de ser a favor ou contra a doação de órgãos, mas, idade $(p=0,148)$ e religião $(p=0,729)$, não.

Em relação à intenção de doar seus próprios órgãos após a morte, $82,8 \%$ tinham essa disposição, $9 \%$ não tinham opinião sobre o assunto e $8,2 \%$ não tencionavam isso. Foi possível perceber que a escolaridade $(p=0,027)$ é um fator que interfere na decisão de doar seus órgãos, mas idade $(p=0,293)$ e religião $(p=0,915)$, não. Dentre os participantes, $70,5 \%$ já conversaram com a família sobre sua opinião a respeito da doação de seus órgãos após a morte (Tabela 2). Através da correlação de Pearson, 
notou-se que a conversa com a família sobre a decisão de ser ou não doador de órgãos apresentou relação com a autorização da doação dos próprios órgãos após a morte $(p=0,013)$.

Tabela 1: Perfil do público em estudo e porcentagem favorável à doação de órgãos e tecidos para transplante

\begin{tabular}{|c|c|c|c|c|}
\hline & $\mathbf{N}$ & $\%$ & $\begin{array}{c}\text { A Favor } \\
\text { (\%) }\end{array}$ & p \\
\hline \multicolumn{5}{|l|}{ Sexo } \\
\hline Feminino & 100 & 82 & 97 & \\
\hline Masculino & 22 & 18 & 95 & \\
\hline Idade & & & & 0,148 \\
\hline 18 a 29 & 63 & 51,6 & 98 & \\
\hline 30 a 39 & 32 & 26,2 & 96,9 & \\
\hline 40 a 49 & 13 & 10,7 & 92 & \\
\hline 50 a 59 & 8 & 6,6 & 87,5 & \\
\hline$>60$ & 6 & 4,9 & 100 & \\
\hline Escolaridade & & & & 0,018 \\
\hline Ensino Fundamental Incompleto & 1 & 0,8 & 0 & \\
\hline Ensino Fundamental Completo & 8 & 6,6 & 100 & \\
\hline Ensino Médio Incompleto & 4 & 3,3 & 100 & \\
\hline Ensino Médio Completo & 15 & 12,3 & 86,7 & \\
\hline Ensino Superior Incompleto & 75 & 61,5 & 99 & \\
\hline Ensino Superior Completo & 8 & 6,6 & 100 & \\
\hline Pós Graduação & 11 & 9,0 & 100 & \\
\hline Religião & & & & 0,729 \\
\hline Católico & 71 & 58,2 & 97 & \\
\hline Evangélico & 14 & 11,5 & 93,9 & \\
\hline Espírita & 12 & 9,8 & 91,7 & \\
\hline Outra & 25 & 20,5 & 100 & \\
\hline
\end{tabular}

Quando questionados se autorizariam a doação de órgãos de um membro da família que não tivesse manifestado o seu desejo em vida, $58 \%$ responderam que autorizariam a doação, $23 \%$ não autorizariam e $19 \%$ ficaram indecisos. Porém se o membro da família tivesse manifestado o desejo favorável em vida, 97,6\% autorizariam a doação, 1,6\% não autorizaria e 0,8\% ficaram indecisos.

Entre os motivos citados para se tornar um doador de órgãos, o principal foi ajudar o próximo/salvar vidas, e os principais motivos que levaram as pessoas a não doar os órgãos foram: apego ao familiar e religião (Tabela 3).

Dentre todos os 122 participantes, 82\% afirmaram já ter recebido algum tipo de informação sobre doação de órgãos e tecidos e $18 \%$ nunca tiveram acesso a informações referentes ao tema. Os participantes que declararam ter recebido informações sobre o assunto relataram que estas foram adquiridas através de mídias como televisão, rádio, jornal e internet (45\%), profissionais da saúde (45\%), outras campanhas educativas $(21 \%)$ e por meio dos amigos $(8 \%)$.

Tabela 2: Relação entre a autorização para a doação de órgãos e a conversa com a família

\begin{tabular}{|c|c|c|c|c|c|}
\hline & & & \multicolumn{2}{|c|}{$\begin{array}{c}\text { Já conversou com } \\
\text { a família sobre a } \\
\text { decisão de ser ou } \\
\text { não doador }\end{array}$} & \multirow[b]{2}{*}{ Total } \\
\hline & & & Sim & Não & \\
\hline \multirow{8}{*}{$\begin{array}{l}\text { Tem intenção } \\
\text { de doar seus } \\
\text { órgãos após } \\
\text { a morte }\end{array}$} & \multirow[b]{2}{*}{ Sim } & $\mathrm{n}$ & 76 & 25 & 101 \\
\hline & & $\%$ & 62,3 & 20,5 & 82,8 \\
\hline & \multirow[b]{2}{*}{ Não } & $\mathrm{n}$ & 6 & 4 & 10 \\
\hline & & $\%$ & 4,9 & 3,3 & 8,2 \\
\hline & \multirow{2}{*}{$\begin{array}{l}\text { Não tem } \\
\text { oipinião }\end{array}$} & $\mathrm{N}$ & 4 & 7 & 11 \\
\hline & & $\%$ & 3,3 & $5,7 \%$ & 9,0 \\
\hline & \multirow{2}{*}{ Total } & $N$ & 86 & 36 & 122 \\
\hline & & $\%$ & 70,5 & 29,5 & 100 \\
\hline
\end{tabular}

Tabela 3: Motivos favoráveis e não favoráveis à doação de órgãos

\begin{tabular}{ll}
\hline Motivos para se tornar doador & $\%$ \\
Ajudar o próximo/ Salvar vidas & 85 \\
Reaproveitamento dos órgãos & 22 \\
Possibilidade de vir a necessitar de um transplante & 16 \\
Necessidade social de doação & 11 \\
História pessoal ou familiar de transplante & 10 \\
Não sei, não sou doador & 7 \\
Motivos religiosos & 2 \\
Motivos para não doar & $\%$ \\
Apego ao familiar & 52 \\
Religião & 40 \\
Medo de erro no diagnóstico de morte encefálica & 30 \\
Medo de corrupção e comércio de órgãos & 24 \\
Mutilação do corpo & 24 \\
Falta de confiança no sistema de saúde & 21 \\
\hline
\end{tabular}

Quanto à atitude a ser tomada na decisão de se tornar um doador de órgãos, $79 \%$ responderam que é preciso pedir que os familiares autorizem a doação no caso de sua morte, $30 \%$ acharam que também é necessário colocar essa opção no documento de identidade, 5\% que se deve telefonar à central de transplantes para autorizar e $8 \%$ não souberam responder. 
Com relação à possibilidade de doar algum órgão em vida, $97,5 \%$ acreditavam que é possível e $2,5 \%$ não tinham esse conhecimento. Quanto aos órgãos e tecidos que podem ser doados nesta condição, $86 \%$ citaram o rim, $74 \%$ a medula óssea, $37 \%$ o fígado, $18 \%$ a pele, $7 \%$ o pulmão, $2 \%$ o intestino e $2 \%$ o coração. A percepção dos participantes quanto aos órgãos que podem ser doados após a morte encefálica foi apresentada na Tabela 4.

Tabela 4: Conhecimento dos participantes sobre os órgãos e tecidos que podem ser doados após a morte encefálica

\begin{tabular}{lccc}
\hline & Sim (\%) & Não (\%) & Não sei (\%) \\
\hline Baço & 21 & 12 & 67 \\
Córnea & 82 & 3 & 15 \\
Ossos & 46 & 11 & 43 \\
Pâncreas & 39 & 10 & 51 \\
Bexiga & 20 & 16 & 64 \\
Rim & 85 & 0 & 15 \\
Pele & 70 & 3 & 27 \\
Coração & 86 & 3 & 11 \\
Fígado & 72 & 5 & 23 \\
Medula Óssea & 58 & 7 & 35 \\
Vesícula & 16 & 20 & 64 \\
Pulmão & 66 & 8 & 26 \\
Intestino & 33 & 17 & 56 \\
Estômago & $\mathbf{2 4}$ & $\mathbf{1 7}$ & $\mathbf{5 9}$ \\
\hline
\end{tabular}

Ao serem questionados quanto à condição em que se encontra um paciente diagnosticado com morte encefálica, $52,5 \%$ afirmaram que essa pessoa está morta, $24,6 \%$ que está parcialmente viva, $13,9 \%$ que está em coma e $9 \%$ declararam não saber seu significado.

A associação entre o nível de escolaridade e o conhecimento do conceito de morte encefálica foi demonstrada na Tabela 5.

Quanto à confiança no diagnóstico de morte encefálica estabelecido pelo médico, $41,8 \%$ afirmaram que esse está sempre correto e $58,2 \%$ que existe possibilidade de erro e o paciente pode estar vivo; esta percepção não influenciou na decisão de doar seus órgãos após a morte $(p=0,192)$.

Mais da metade da população estudada, 68,9\%, acreditavam na existência de venda de órgãos no Brasil, $10,6 \%$ não acreditavam e 20,5\% não tinham opinião.

Em relação aos fatores que influenciaram na ordem da lista de espera por um transplante, foi mencionada a gravidade da doença (76\%), o tempo que a pessoa estava na lista de espera $(50 \%)$, as condições financeiras (16\%) e o plano de saúde (13\%). A grande maioria, $95,1 \%$, acreditava que os órgãos doados não eram suficientes para todas as pessoas que aguardam na lista de espera por um transplante, enquanto $1,6 \%$ achavam que eram suficientes e $3,3 \%$ não souberam responder.

Tabela 5: Relação entre o conhecimento do significado de morte encefálica e o nível de escolaridade

\begin{tabular}{|c|c|c|c|c|c|c|c|}
\hline & & & \multicolumn{4}{|c|}{$\begin{array}{l}\text { Quando uma pessoa está em morte encefálica, } \\
\text { ela está }\end{array}$} & \multirow{2}{*}{ TOTAL } \\
\hline & & & Morta & Em coma & $\begin{array}{l}\text { Parcialmente } \\
\text { viva }\end{array}$ & Não sei & \\
\hline \multirow{14}{*}{ ESCOLARIDADE } & \multirow{2}{*}{ Fundamental incompleto } & $\mathrm{N}$ & 0 & 0 & 0 & 1 & 1 \\
\hline & & $\%$ & 0 & 0 & 0 & 0,8 & 0,8 \\
\hline & \multirow{2}{*}{ Fundamental completo } & $\mathrm{N}$ & 4 & 3 & 1 & 0 & 8 \\
\hline & & $\%$ & 3,3 & 2,5 & 0,8 & 0 & 6,6 \\
\hline & \multirow{2}{*}{ Médio incompleto } & $\mathrm{N}$ & 1 & 1 & 1 & 1 & 4 \\
\hline & & $\%$ & 0,8 & 0,8 & 0,8 & 0,8 & 3,3 \\
\hline & \multirow{2}{*}{ Médio completo } & $\mathrm{N}$ & 6 & 2 & 4 & 3 & 15 \\
\hline & & $\%$ & 4,9 & 1,6 & 3,3 & 2,5 & 12,3 \\
\hline & \multirow{2}{*}{ Superior incompleto } & $\mathrm{N}$ & 40 & 10 & 21 & 4 & 75 \\
\hline & & $\%$ & 32,8 & 8,2 & 17,2 & 3,3 & 61,5 \\
\hline & \multirow{2}{*}{ Superior completo } & $\mathrm{N}$ & 4 & 1 & 2 & 1 & 8 \\
\hline & & $\%$ & 3,3 & 0,8 & 1,6 & 0,8 & 6,5 \\
\hline & \multirow{2}{*}{ Pós-Graduação } & $\mathrm{N}$ & 9 & 0 & 1 & 1 & 11 \\
\hline & & $\%$ & 7,4 & 0 & 0,8 & 0,8 & 9 \\
\hline & \multirow{2}{*}{ TOTAL } & $\mathbf{N}$ & 64 & 17 & 30 & 11 & 122 \\
\hline & & $\%$ & 52,5 & 13,9 & 24,6 & 9 & 100 \\
\hline
\end{tabular}




\section{DISCUSSÃO}

Visando atender ao objetivo primordial de pesquisa, inicialmente, traçou-se o perfil do público em estudo, depois, discutiu-se em duas etapas a opinião e o conhecimento da amostra sobre morte encefálica e o processo de doação de órgãos e tecidos para transplante.

\section{Identificação do perfil dos participantes}

O perfil dos participantes deste estudo assemelha-se ao encontrado por Teixeira, ${ }^{8}$ Felix e Santos ${ }^{10}$ no que se refere à religião e idade, com predominância da religião católica e da idade correspondente a adultos jovens (18 a 39 anos). Mesmo que em ambos os estudos tenha predominado o sexo feminino na amostra, nesta pesquisa a prevalência de mulheres sobressaiu, provavelmente em decorrência da maior procura destas por serviços de saúde,${ }^{11}$ sendo que um dos locais de coleta de dados foi instituição de assistência hospitalar. Entretanto, o nível de escolaridade encontrado neste trabalho, que é em sua maioria de ensino superior incompleto, destoa do achado por Teixeira, ${ }^{8}$ Felix e Santos, ${ }^{10}$ no qual maior parcela da população possuía ensino médio.

\section{Opinião dos participantes sobre o processo de doação de órgãos}

Segundo dados do Registro Brasileiro de Transplantes, o número de potenciais doadores é de 52 por milhão de população (pmp). Dentre esses, o percentual de recusa das entrevistas familiares é de $36 \%$, finalizando com um número de doadores efetivos de 18,4 pmp/ano. ${ }^{4} \mathrm{~A}$ recusa familiar vem se mostrando como uma das principais causas da não efetivação da doação de órgãos, e essa negativa tem motivos diversos. ${ }^{6}$ Com isso, buscou-se investigar a opinião da população no que se refere à doação de órgãos e tecidos.

Ainda que, segundo a ABTO, a aceitação familiar para a doação seja de $57 \%$, esta pesquisa mostrou que $96,7 \%$ da população estudada foi a favor da doação de órgãos, semelhante ao encontrado por Coelho ${ }^{12}$ e Felix e Santos ${ }^{10}$ que obtiveram, respectivamente, um valor de $87,8 \%$ e $86 \%$ favoráveis à doação de órgãos. Assim como nos levantamentos realizados por Coelho ${ }^{12}$ e Teixeira, ${ }^{8}$ pela análise dos dados apresentados neste estudo não se pode afirmar que haja influência da idade ou da religião na opinião de ser a favor ou contra a doação de órgãos. Entretanto, nesta pesquisa foi possível estabelecer relação significativa entre o nível de escolaridade e o posicionamento favorável à doação, diferente do encontrado pelos pesquisadores citados anteriormente. Isto pode ser explicado pelo fato de mais de $70 \%$ das pessoas possuírem escolaridade de ensino superior incompleto à pós-graduação. Portanto, fica evidente que o nível de instrução é diretamente proporcional ao posicionamento a favor da doação.

Dentre os principais motivos pelos quais as pessoas foram favoráveis à doação destacou-se o desejo de ajudar o próximo e salvar vidas, corroborando com o encontrado por Coelho, ${ }^{12}$ Felix e Santos. ${ }^{10}$ Nesse sentido, Rossato ${ }^{13}$ afirmou que as famílias veem a doação de órgãos como um ato de amor pelo familiar e pelo próximo, como uma chance de oportunizar a sobrevivência do receptor, muitas vezes dando até certo sentido para a morte e ajudando a confortar a família no momento da perda.

Apesar da maior parte das pessoas mostraremse sensibilizadas à doação de órgãos, ainda houve percepção limitada para aceitação, sendo apontado como os principais pretextos à não doação o apego ao familiar, a religião e o medo de erro no diagnóstico de morte encefálica. Similar ao encontrado na pesquisa de Rodrigues, ${ }^{14}$ Felix e Santos. ${ }^{10}$ Segundo Rosário ${ }^{15}$ muitos familiares utilizam os motivos religiosos como subterfúgio no momento da tomada de decisão, porém no Brasil nenhuma religião é desfavorável à doação de órgãos. Nota-se que, na verdade, as famílias ficam à espera de um milagre e que as crenças culturais são mais expressivas que as religiosas. Essa esperança, muitas vezes, está ligada à não compreensão do diagnóstico de morte encefálica, pois as famílias não conseguem entender que um corpo que ainda respira, mantém temperatura e batimentos cardíacos, possa estar realmente morto. ${ }^{6}$

No que se refere à confiança no diagnóstico de morte encefálica estabelecido pelo médico, mais da metade do público no estudo acreditava que existia possibilidade de erro e o paciente ainda poderia estar vivo. Achado semelhante ao encontrado por Coelho ${ }^{12}$ e Teixeira, ${ }^{8}$ que obtiveram taxa de $59 \%$ e $85,3 \%$, respectivamente de participantes que acreditavam que o médico poderia se equivocar ao dar o diagnóstico de morte encefálica. Por esse motivo, muitos familiares no momento da decisão de doar os órgãos não se sentiam seguros, acreditando que estavam sendo negligentes com o familiar e antecipando sua morte ao autorizarem o desligamento dos aparelhos. ${ }^{13}$

A falta de confiança no sistema de saúde também vem se mostrando um fator significante na recusa à doação. Algumas pessoas acreditam no tráfico de órgãos, e que caso optem pela doação, a equipe médica possa induzir a morte do paciente para posterior venda de órgãos. ${ }^{15}$ Neste contexto, foi relevante que apenas 10,6\% da 
população estudada em Caxias do Sul afirmaram ter certeza da inexistência do comércio de órgãos no Brasil. O que se encontra em consonância com estudo realizado com a população de Curitiba, onde a maioria $(81,3 \%)$ acreditava na existência de venda de órgãos. ${ }^{12}$

Quando questionados se autorizariam a doação de seus órgãos após a morte, $82,8 \%$ responderam afirmativamente. Entretanto, esse número foi reduzido em comparação ao percentual favorável à doação. No que se refere à doação de órgãos de um membro da família, a autorização depende expressivamente do manifestado pelo doador em vida, visto que $97,6 \%$ autorizariam a doação de órgãos de um familiar que se posicionou favorável à doação, e somente $58 \%$ autorizariam quando o desejo do potencial doador for desconhecido. Este último número também foi encontrado por Felix e Santos, ${ }^{10}$ num estudo semelhante realizado em Goiás.

Pesquisa realizada em São Paulo identificou que 64\% das famílias que foram entrevistadas para a doação de órgãos desconheciam a vontade do familiar, ${ }^{6}$ sendo esse motivo frequentemente declarado por elas no momento da recusa à doação, complementando que se a pessoa tivesse comunicado em vida seu desejo de ser doador, a família teria respeitado essa decisão. ${ }^{15}$ Neste contexto, nota-se a importância de conversar sobre esse assunto no âmbito familiar, pois o conhecimento do desejo do potencial doador possibilita mais segurança à família no momento da decisão. ${ }^{16}$ Em contrapartida, $70,5 \%$ dos participantes desta pesquisa afirmaram já ter informado à família sobre sua decisão de ser ou não doador, fator propositivo para o processo de doação de órgãos.

Grande parte da população já teve acesso a informações referentes ao processo de doação de órgãos, sendo esse um fator positivo para a promoção da doação. Os principais meios pelos quais adquiriram informações foram as mídias e os profissionais de saúde. Neste contexto, cabe ressaltar que o papel do enfermeiro não é apenas prestar cuidados e viabilizar órgãos para o transplante, é também educar, passar informações à população e promover a mudança de atitudes. ${ }^{17}$ Segundo Matte ${ }^{18}$ a distribuição de informações deve ocorrer a toda a população, e não somente no momento da entrevista familiar para a doação de órgãos, pois quanto maior o conhecimento das pessoas sobre o tema, maior será a chance de expressarem o seu desejo de ser ou não doador de órgãos.

\section{Conhecimento dos participantes sobre morte encefálica e doação de órgãos:}

O conhecimento sobre morte encefálica é uma variável que pode interferir na tomada de decisão sobre a doação, sendo as recusas, na maior parte das vezes, por desconhecimento, medos e dúvidas. A falta de compreensão e de informação é fator negativo para a doação de órgãos e tecidos ${ }^{10}$ e o desconhecimento sobre o assunto é a principal dificuldade para dar seguimento ao processo de doação. ${ }^{16}$ Nesse sentido, buscou-se identificar o conhecimento da população em estudo no que se refere ao processo de doação de órgãos e tecidos.

Pela análise dos questionários, percebeu-se que apenas $52,5 \%$ do público entrevistado entendiam o significado de morte encefálica, ainda que o nível de escolaridade dos participantes nesta pesquisa tenha sido mais alto do que outras casuísticas. Felix e Santos $^{10}$ apontaram que $74 \%$ de sua amostra conhecia o conceito correto para morte encefálica. Entretanto, Teixeira ${ }^{8}$ relatou que $77 \%$ dos indivíduos por ele entrevistados acreditavam que o paciente com o diagnóstico de morte encefálica estaria parcialmente vivo ou em condições de viver, mostrando não conhecer seu significado. Rossato ${ }^{13}$ afirmou que 0 diálogo foi fator que auxiliou as pessoas a entender o conceito de morte encefálica, além de mudar a opinião dos familiares com relação ao pensamento primário de que o paciente ainda possa estar vivo.

Conforme a legislação vigente no Brasil, a retirada dos órgãos depende exclusivamente da autorização familiar. ${ }^{3}$ Os resultados aqui mostrados indicaram que a maioria das pessoas (79\%) possuía esse conhecimento, porém, algumas ainda acreditavam que essa opção também poderia ser colocada no documento de identidade ou que existiam outras formas de autorizar a doação. Percebese uma expressiva diferença quando comparamos esse dado com o exposto por Coelho, ${ }^{12}$ no qual somente $49 \%$ da população tinham conhecimento da conduta a ser tomada ao decidir tornar-se doador.

Outro dado relevante foi que $90,2 \%$ da população estudada ainda desconheciam a idade em que é possível tornar-se doador. De acordo com o Conselho Federal de Medicina (CFM) ${ }^{19}$ é permitida a doação de órgãos a partir dos sete dias de vida, não havendo limite máximo de idade. Isto se deve ao fato de que não se pode estabelecer o diagnóstico de morte encefálica antes dos sete dias de vida.

Em conformidade com a legislação brasileira, grande parte da amostra tinha conhecimento de que é possível doar alguns órgãos e tecidos em vida. Entre os mais citados por eles, estão o rim, a medula óssea e o fígado, porém, muitos ainda desconheciam que era possível doar parte do pulmão. Ainda, segundo a legislação, é permitida a doação de órgãos e tecidos em vida para transplantes, contanto que essa retirada não cause comprometimento das aptidões vitais, mutilação ou deformação ao doador, e corresponda a uma necessidade terapêutica indispensável ao receptor. ${ }^{3}$ 
A população em estudo demonstrou pouco conhecimento quanto aos órgãos que podem ser doados após a morte encefálica, citando em sua maioria, o coração, os rins e as córneas, e dando menos ênfase aos ossos, pâncreas e intestino. Dado similar ao encontrado por Coelho, ${ }^{12}$ onde a população estudada também se referiu mais ao coração $(93,5 \%)$, aos rins $(94,1 \%)$ e as córneas $(91,3 \%)$. Segundo o Ministério da Saúde os órgãos que podem ser doados após a morte encefálica são: coração, pulmão, rim, fígado, pâncreas e intestino, além de tecidos como pele, córneas, ossos, cartilagem, tendão e valvas cardíacas. ${ }^{2}$

Todos os órgãos obtidos de doadores falecidos devem ser distribuídos conforme o Sistema de Lista Única, que é composto por potenciais receptores que estão inscritos no Cadastro Técnico Único, obedecendo a critérios de inclusão específicos para o tipo de órgão ou tecido. ${ }^{20}$ A lista é única por estado ou por região e organizada através de critérios que respeitam as condições clínicas de cada paciente. Os fatores determinantes para a ordem da lista dependem da compatibilidade sanguínea entre os órgãos ofertados e o receptor, do tempo em que o paciente aguarda na lista de espera e, principalmente, da gravidade da doença. ${ }^{2}$

Com relação a isso, a maioria dos participantes da pesquisa identificou os fatores que influenciam na ordem da lista de espera. Entretanto, 29\% pensavam que as condições financeiras ou o plano de saúde poderiam influenciar também. Esse equívoco também foi identificado por Coelho, ${ }^{12}$ pois em sua pesquisa, a maioria dos entrevistados $(62,6 \%)$ acreditava que os ricos tinham mais chances de receber um transplante.

Atualmente, mais de 37 mil pacientes estão ativos na lista de espera por um transplante, mostrando que o número de doações, apesar de crescente, ainda não é suficiente. ${ }^{4}$ Ao serem indagados sobre essa situação, a expressiva maioria dos participantes demonstrou percepção de que os órgãos que são doados são insuficientes para todas as pessoas que aguardam na lista de espera.

Ressalta-se que este estudo apresentou fragilidades, devido à limitação de recursos para a coleta de dados. O número de indivíduos da amostra não foi expressivo e os locais onde foram coletados os dados podem ter influenciado o perfil dos participantes, principalmente no que se refere a sexo e escolaridade, fazendo com que os dados obtidos possam diferir da população em geral. Assim, os resultados ora obtidos, não permitem generalização. Outros estudos com amostra mais significativa e representativa da população são sugestões para investigações dessa temática.
Visto que grande parte das pessoas tem acesso às informações relativas ao processo de doação de órgãos propagadas principalmente pelas mídias e profissionais de saúde, cabe levantar alguns questionamentos que podem servir como direcionamentos para futuros estudos: Por que as pessoas ainda apresentam crenças, erros de conceitos e falta de informação sobre o assunto? Será que não falta a formação de uma cultura da doação desde a idade escolar das crianças? O que falta, o que é preciso para não apenas "informar" as pessoas, mas sim "educar" levando a mudanças de atitudes neste contexto?

\section{CONCLUSÃO}

Apesar da grande evolução no processo de doação de órgãos, o número de doadores efetivos ainda é insuficiente para atender as demandas da lista de espera por um transplante. Diante disto, faz-se necessária maior interação das pessoas nesse assunto, para que através da divulgação e debate de opiniões se alcance o maior número de efetivação nas doações.

Percebeu-se que a maioria da população estudada tem uma atitude positiva em relação à doação de órgãos. Porém, o número de recusas familiares ainda é grande, o que pode estar relacionado à falta de confiança no diagnóstico de morte encefálica e no sistema de saúde, visto que a população ainda teme a comercialização de órgãos, e acredita que condições financeiras possam interferir na distribuição dos órgãos captados. Demonstraram conhecimento sobre alguns aspectos do processo de doação e transplante de órgãos, mas desconheciam outros, como o significado de morte encefálica, idade em que é possível tornar-se doador e órgãos que podem ser doados após a morte.

Foi possível identificar que a autorização para a doação depende, significativamente, do que foi manifestado pelo doador em vida, mostrando que a discussão do tema no ambiente familiar é indispensável para o sucesso dos programas de transplantes.

A população, em sua maioria, possui informações acerca do processo de doação de órgãos, porém, muitas vezes essas informações não são suficientes para esclarecer todas as dúvidas pertinentes. Com isso, nota-se a necessidade de mais campanhas educativas visando maior esclarecimento sobre o tema e promovendo incentivo à doação de órgãos, para assim possibilitar o aumento do número de doadores, pois quanto maior a compreensão da família sobre o processo de doação de órgãos e morte encefálica, maior será a segurança no momento da decisão. 


\section{ABSTRACT}

Purpose: To identify the knowledge and opinion of a sample of the population of the city of Caxias do Sul about encephalic death and organ and tissue donation for transplantation. Methods: This is an exploratory study with a quantitative approach performed with 122 residents of the city of Caxias do Sul - Rio Grande do Sul, randomly selected among the population over 18 years old. Data collection was performed in the waiting room of a medium-sized hospital care and in a private college institution from August to September of 2018. Data were analyzed through the IBM SPSS Software, by linear regression and the Pearson correlation, considering as significance level $p<0.05$. Results: the majority of participants $(96.7 \%)$ is in favor of organ donation, and $(82.8 \%)$ would authorize the donation of their organs after death, having as main motivator helping others and save lives. The main reasons against the donation are attachment to family and religion. Many believe in the existence of organ trading in Brazil, and that there is a possibility of error in the encephalic death diagnosis established by the doctor. Most have already received information on organ donation mainly through the media and health professionals. Conclusion: the majority of participants has a positive attitude toward organ donation, and they present partial knowledge about the donation process. It is required more educational campaigns and incentives to donate, as the greater the understanding of the family, the greater the security at the moment of decision to the organ donation.

Keywords: Tissue and Organ Procurement; Organ Transplantation; Brain Death; Knowledge.

\section{REFERÊNCIAS}

1. Westphal GA, Garcia VD, Souza RL, Franke CA, Vieira KD, Birckholz VRZ, et al. Diretrizes para avaliação e validação do potencial doador de órgãos em morte encefálica. Revista Brasileira de Terapia Intensiva. 2016;28(3):220-55.

2. Brasil. Ministério da Saúde. Doação de Órgãos: transplantes, lista de espera e como ser doador. 2020. Disponível em: <http://portalms.saude.gov.br/saude-dea-z/doacao-de-orgaos>. Acesso em: 25 jul. 2020.

3. Brasil. Decreto n 9.175, de 18 de outubro de 2017. Regulamenta a Lei n 9.434, de 4 de fevereiro de 1997, para tratar da disposição de órgãos, tecidos, células e partes do corpo humano para fins de transplante e tratamento. Brasília: 2017. Disponível em: <http://www. planalto.gov.br/ccivil_03/_ato2015-2018/2017/decreto/ D9175.htm>. Acesso em 25 jul. 2020.

4. Associação Brasileira de Transplante de Órgãos ABTO. Registro Brasileiro de Transplantes: Dados Numéricos da doação de órgãos e transplantes realizados por estado e instituição no período janeiro I março - 2020. São Paulo: ano XXVI, n 1, 2020. Disponível em: <http://www.abto.org.br/abtov03/Upload/ file/RBT/2020/RBT-2020-1trim-leitura.pdf >. Acesso em: 25 jul. 2020.
5. Associação Brasileira de Transplante de Órgãos - ABTO Registro Brasileiro de Transplantes: Dados Numéricos da doação de órgãos e transplantes realizados por estado e instituição no período janeiro / junho - 2018. São Paulo: ano XXIV, n² 2, 2018. Disponível em: <http://www.abto.org.br/ abtov03/Upload/file/RBT/2018/rbt2018-1-populacao.pdf>. Acesso em: 21 set. 2018.

6. Pessoa JLE, Schirmer J, Roza BA. Avaliação das causas de recusa familiar a doação de órgãos e tecidos. Acta Paulista de Enfermagem. 2013;26(4):323-30.

7. Associação Brasileira de Transplante de Órgãos - ABTO Registro Brasileiro de Transplantes: Dimensionamento dos Transplantes no Brasil e em cada estado (2010-2017). São Paulo, ano XXIII, $\mathrm{n}^{\circ} 4$, 2017. Disponível em: <http://www.abto. org.br/abtov03/Upload/file/RBT/2017/rbt-imprensa-leituracompressed.pdf>. Acesso em: 07 mar. 2018.

8. Teixeira RKC, Gonçalves TB, Silva JAC. A intenção de doar órgãos é influenciada pelo conhecimento populacional sobre morte encefálica? Revista Brasileira de Terapia Intensiva. 2012;24(3):258-62.

9. Brasil. Ministério da Saúde. Conselho Nacional de Saúde. Resolução n 466, de 12 de dezembro de 2012. Brasília: 2012. Disponível em: <http://bvsms.saude.gov.br/bvs/saudelegis/ cns/2013/res0466_12_12_2012.html>. Acesso em: 25 mar. 2018. 
10. Felix MB, Santos WL. Conhecimento da população do município de Valparaíso de Goiás sobre o processo de doação de órgãos para transplantes. Revista de Divulgação Científica Sena Aires. 2015;4(1):3-10.

11. Brasil. Ministério da Saúde. Pesquisa Nacional de Saúde: 2013: acesso e utilização dos serviços de saúde, acidentes e violências: Brasil, grandes regiões e unidades da federação / IBGE, Coordenação de Trabalho e Rendimento. Rio de Janeiro: IBGE, 2015. 100p. Disponível em: <https:// biblioteca.ibge.gov.br/visualizacao/livros/liv94074.pdf>. Acesso em: 01 nov. 2018.

12 . Coelho JCU, Cilião C, Parolin MB, Freitas ACT, Filho OPG, Saad DT, et al. Opinião e conhecimento da população da cidade de Curitiba sobre doação e transplante de órgãos. Revista da Associação Médica Brasileira. 2007;53(5):421-5.

13. Rossato GC, Girardon-Perlini NMO, Begnini D, Beuter M, Camponogara, S, Flores CL. Doar ou não doar: a visão de familiares frente à doação de órgãos. Revista Mineira de Enfermagem. 2017;21:e-1056.

14. Rodrigues SLL, Neto JBEF, Sardinha LAC, Araujo S, Zambelli HJL, Boin IFSF, et al. Perfil de doadores efetivos do serviço de procura de órgãos e tecidos. Revista Brasileira de Terapia Intensiva. 2014;26(1):21-7.

15. Rosário EN, Pinho LG, Oselame GB, Neves EB. Recusa familiar diante de um potencial doador de órgãos. Cadernos de Saúde Coletiva. 2013;21(3):260-6.
16. Barreto BS, Santana RJB, Nogueira EC, Fernandez $\mathrm{BO}$, Brito FPG. Fatores relacionados à não doação de órgãos de potenciais doadores no estado de Sergipe, Brasil. Revista Brasileira de Pesquisa em Saúde. 2016;18(3):40-8.

17 Moraes El, Santos MJ, Merighi MAB, Massarollo MCKB. Vivência de enfermeiros no processo de doação de órgãos e tecidos para transplante. Revista LatinoAmericana de Enfermagem. 2014;22(2):226-33.

18. Matte NL. Tráfico de órgãos: A (im)possibilidade da legalização da comercialização de órgãos no brasil e os entraves à doação. Monografia de Graduação em Direito, Lajeado: Centro Universitário Univates; 2017. 91p.

19. Conselho Federal de Medicina - CFM. Resolução CFM 2.173/17. Define os critérios do diagnóstico de morte encefálica. Brasília: 2017. Disponível em: <http://www.saude.rs.gov.br/upload/arquivos/ carga20171205/19140504-resolucao-do-conselhofederal-de-medicina-2173-2017.pdf>. Acesso em: 30 mar. 2018.

20. Brasil. Portaria $n^{\circ} 2.600$, de 21 de outubro de 2009. Aprova o Regulamento Técnico do Sistema Nacional de Transplantes. Brasília: 2009. Disponível em: <http://bvsms.saude.gov.br/bvs/saudelegis/gm/2009/ prt2600_21_10_2009.html>. Acesso em: 22 abr. 2018. 